\title{
Let's Open the Doors
}

THIS ISSUE of Oceanography celebrates five decades of international partnerships. Nowhere was the value of those kinds of partnerships more evident than at the 2008 Ocean Sciences Meeting recently concluded in Orlando, Florida. More than 4000 attendees came from scores of countries, academia, government (at all levels), industry, and nongovernmental organizations to give talks, attend plenary sessions, discuss posters, enjoy the exhibit hall, reinvigorate old friendships, and initiate new partnerships. The Oceanography Society, the American Society of Limnology and Oceanography, the American Geophysical Union, and the Estuarine Research Federation all came together for what turned out to be a seminal event.

What was remarkable to me, however, was that for every positive aspect of the meeting, I wondered if we weren't also missing some extraordinary opportunities. The icons of our community were present, both speaking and listening. As one walked through the conference venue, it was not unusual to run into some of the pioneers of our field. But the number of press releases and interviews were surprisingly spare. The issues that were covered in the talks and posters represented some of the most stunning and critical findings, not only for the oceanographic community but also for society in general, with direct relevance to global climate change, management of diminishing resources, and safety of the global population. Yet the engagement of decision makers and legislators was negligible. The technological advances and new capabilities for platforms, sensors, and systems-both on display in the exhibit hall and under discussion in some of the technology sessions-were truly state of the art. Yet the exhibit hall included virtually no major corporations or global businesses. In short, we had:

- Fascinating science-and no media coverage

- Controversial issues-and no policy-makers

- Extraordinary technology-and no big business
Please understand I mean no criticism of the wonderful teams who developed and organized this extraordinary event. Their coolness under fire and willingness to put forth under an overwhelming community response are truly admirable and highly appreciated. My question, though, is for our community at large. Are we missing a bet? Do we just not care about some of these issues? One of the benefits of my job is that I am afforded the opportunity to interact with an array of different scientific communities. I also am closely connected with the processes and mechanisms for soliciting resources for our community. I cannot help but notice that many of those scientific communities that actively reach out to the media, the policymakers, and big business are often more successful than we oceanographers in seeing real growth in our research accounts.

A special note: Jon Sharp, University of Delaware biogeochemist and meeting co-chair, understands this issue well. He worked very hard to address some of these concerns in the special forum that he organized one evening in Orlando. During the session titled "Does Science Really Matter?" we heard some wonderful views from very knowledgeable and opinionated members of the media, the communications industry, and our own oceanographic community. From the audience reaction, I believe the concerns I've expressed here are shared by many.

So, in light of the theme of this issue-partnerships-my question is simple. Should we think more seriously of building active partnerships beyond our scientific oceanographic community, and reflecting those in how we conduct our meetings in the future? It's our community, we're very proud of it...maybe it is time to invite some others to the party.

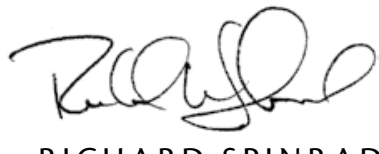

RICHARD SPINRAD, TOS PRESIDENT 